Revista Iberoamericana, Vol. LXXXV, Núm. 268, Julio-Septiembre 2019, 963-979

\title{
LA MULTICULTURALIDAD EN MÉXICO EN EL PROGRAMA EDUCATIVO VENTANA A MI COMUNIDAD
}

\author{
POR \\ Milvet Alonso \\ University of Georgia
}

Por años la apuesta en política y educación respecto a las comunidades indígenas ha sido la de la incorporación de dichas culturas a un plan nacional homogéneo. Ciertamente la población mexicana está constituida por varios grupos raciales y culturales, sin embargo una de las polarizaciones más grandes ha sido la de indígena y español (Knight 72). En el año, 2006 la Secretaría de Educación Pública lanzó una serie de videos titulada Ventana a mi comunidad con la cual se pretendió difundir en las escuelas a nivel básico información sobre las diferentes culturas indígenas en México. El auge de la multiculturalidad en este país en los últimos años y el lanzamiento de esta serie muestran una aparente nueva dinámica entre el estado y las comunidades originarias. Sin embargo, irónicamente es evidente que mientras en unos momentos se quiere revalorar las culturas indígenas a través de programas culturales y educativos, en otros o al mismo tiempo, se obvian tratando de adaptar los mismos programas educativos en cuestión a estándares internacionales.

El concepto de multiculturalismo ha estado en boga en épocas recientes, pero también ha sido problemático por las maneras de interpretarlo y sobre todo de aplicarlo a políticas de estado. El multiculturalismo parte de la observación de que la mayoría de las sociedades contemporáneas contiene múltiples culturas, lo cual las hace 'multiculturales'; esto implica que este concepto es algo que se aprueba, a lo que se le opone o simplemente se tolera. El multiculturalismo sostiene que la multiplicidad de culturas en una sola sociedad además debe ser reconocida en políticas e instituciones públicas de la sociedad en cuestión (Crowder 7). Asimismo, dicho concepto puede ser visto también como la existencia de identidades culturales en tensión en una sociedad democrática donde pueden contribuir a desestructurarla (Wieviorka 892). En este trabajo, siguiendo líneas de análisis propuestas por Claudio Lomnitz y Analisa Taylor, entre otros investigadores, hago una lectura analítica de algunos de los videos que integran la serie Ventana a mi comunidad, así como los materiales escritos que la acompañan, y que es contrastante con la crítica que algunos maestros e investigadores de las culturas originarias hacen de la llamada educación indígena. Asimismo, a través 
de esta serie observo cómo se ha enmarcado el multiculturalismo dentro de la noción de nacionalismo, reduciendo así el poder político generado al hacer visible la marginación sociopolítica de las minorías.

\section{BREVE PANORÁMA HISTÓRICO}

En el terreno educativo desde el porfiriato hasta la Revolución se tenía la perspectiva del indígena como atrasado y se discutía si tal atraso sería una cuestión biológica hereditaria o cultural. En este último caso se podía cambiar por medio de la educación: “indian 'regeneration' was thus taken to be the primary goal of education, one that would require the remedy of imputed deficits and the extirpation of presumably inferior cultural traits of the 'Indian race'-from language, to customs and dress, to morality" (Eiss 120). Gabriela Nouzeilles explica que entre 1870 y 1940 la constitución de la legitimidad política del Estado requería una identidad única y común, misma que, sin contradecir los valores de la modernidad, distinguiera a su población de otros estadosnación. La heterogeneidad de los pueblos de Latinoamérica, continúa Nouzeilles, se percibía como un obstáculo hacia el progreso, por ello en la segunda mitad del siglo XIX, el positivismo fue una herramienta de la que echaron mano los intelectuales latinoamericanos. De acuerdo con esta investigadora, los ensayos positivistas se usaron como una forma de auto-legitimación de la élite que en realidad eran casi siempre una (re)expresión de formas coloniales de discriminación aunque presentadas en un lenguaje científico. De este contexto emergió la idea de que países como México, con una población predominante que se percibía como inferior, debilitaban el potencial de los estados poscoloniales. La población indígena era presentada como incapaz de ser educada y con una gran resistencia a las demandas del progreso (Nouzeilles 284-286).

Después de la Revolución se planteó la revaloración de la raíz indígena en el mexicano mestizo reflejada en expresiones artísticas tales como el muralismo. En 1921 el ministro de educación, José Vasconcelos, ofreció los muros de diversos espacios públicos a artistas como Diego Rivera, Dr. Atl o Roberto Montenegro donde reflejaban un compromiso con el Arte y con el Pueblo. De esta manera, la imagen indígena se trasladó al arte y dio cuenta del proceso histórico y étnico en el que, a través de la belleza, se iniciara el fin de la marginalidad (Monsiváis 96, 98).

Asimismo, Vasconcelos desde la Secretaría de Educación Públicainició un proyecto para redimir mediante la educación pública promoviendo la enseñanza y la identidad nacional en todos los rincones de México. ${ }^{1}$ La meta más inmediata era disminuir el analfabetismo y a partir de 1924 se privilegió la educación como un importante elemento

Esta secretaría, conocida como la SEP, fue creada en 1921 y durante ese año así como en 1940 extendió su jurisdicción de la capital a las escuelas estatales urbanas y rurales. También absorbió escuelas del sistema estatal y municipal a la vez que creó nuevas (Vaughan 4-25). 
del desarrollo nacional. Vasconcelos, a través de las escuelas y las Misiones culturales, intentó llevar al pueblo la cultura clásica (Monsiváis 115, 116). ${ }^{2}$ Sin embargo, a pesar de algunos avances en el reconocimiento de las culturas indígenas a principios de la década de 1920 como una fuerte base en la cultura mexicana, no se les otorgaba la independencia para establecer y dirigir sus propias metas al considerar que no tenían la información para contribuir a su propia transformación (Vaughan 28).

En lo económico, se intentó la restitución de tierras a los campesinos mediante la Reforma Agraria propuesta por Emiliano Zapata en el Plan de Ayala: “. . . that the towns and citizens that had been dispossessed of land, hills, and water would immediately regain the property of these assets. It defined as the obligation of the 'usurpers' -not of the occupying peasants- the need to demonstrate before the courts their property rights" (Aguilar Camín y Meyer 27). El estado mexicano implementó tal reforma desde el ejido; Nugent y Alonso explican que expropió millones de hectáreas y fueron redistribuidas a los campesinos. ${ }^{3}$ Sin embargo esta medida sirvió, más que para beneficiar a los campesinos, para promover un nacionalismo revolucionario populista (Nugent y Alonso 212). Emiliano Zapata criticó el manejo de tal reforma al sostener que las haciendas eran otorgadas o rentadas a los generales favoritos, y los antiguos latifundios eran reemplazados por terratenientes modernos que hacían uso de las armas (Aguilar Camín y Meyer 65). Tal reforma fracasó y los estragos son visibles en el presente. Debido a la infertilidad de muchas de las tierras y también a que a muchos se les negó tal derecho, la actividad agrícola se vio menguada, propiciando así la emigración a las ciudades y al extranjero.

La disfuncionalidad del modelo económico y cultural que se ha querido imponer a las comunidades tradicionales se hizo evidente para el México occidental a través del levantamiento zapatista en enero de 1994. A veinte años de este levantamiento diferentes voces encontradas ven un movimiento apagado, proyectos no concretizados, añoranza por lo que pudo haber sido o bien, una lucha constante aunque no ya debajo de los reflectores de los medios de comunicación. La revista Proceso dedicó una edición especial al movimiento zapatista en enero de 2014. El breve texto que precede, a modo de editorial, a los diferentes ensayos y entrevistas recuerda la coincidencia de esta sublevación con la imposición del Tratado de Libre Comercio de América del Norte que sacudió el esquema neoliberal. Habla de una luz inicial y la penumbra de la desilusión que vino con los años. Cierra este texto con la siguiente reflexión: "Proceso no olvida aquel episodio y espera contribuir a mantenerlo vivo en la memoria en toda su importancia histórica, por lo que realmente fue para el país y por lo que pudo haber sido" (Editorial 3). Voces críticas apuntan a una falta de congruencia entre las diversas

Creadas en 1923 para entrenar a los maestros (Vaughan 23).

3 El ejido es una unidad territorial creada de acuerdo con las leyes estipuladas durante la Revolución y las políticas agrarias (Nugent y Alonso 209-210).

$111 \frac{\text { Revista Iberoamericana, Vol. LXXXV, Núm. 268, Julio-Septiembre 2019, } 963-979}{\text { ISSN 0034-9631 (Impreso) }}$ 
declaraciones del EZLN (Ejército Zapatista de Liberación Nacional) y sus acciones, en especial en lo referente a dos proyectos que en apariencia coinciden pero son muy divergentes: los deseos de justicia social desde una postura antisistémica y el proyecto de las bases indígenas que buscan mejorar sus condiciones de vida. A pesar de ello con este movimiento se ha logrado promover la dignificación y valoración de las culturas indígenas de México y de otras regiones de Latinoamérica (Legorreta 42, 45).

\section{LA SERIE VENTANA A MI COMUNIDAD}

En años recientes, en el terreno educativo, lo concerniente a la valoración y difusión de las culturas indígenas se ha tratado de ofrecer una perspectiva en la que, en apariencia, los miembros de las diferentes comunidades sean quienes cuenten sus propias tradiciones. En el año 2006 la Secretaría de Educación Pública lanzó un proyecto titulado Ventana a mi comunidad que consiste en una serie de videos, acompañados de cuadernos de trabajo, dirigidos a los niños de escuelas primarias y secundarias del país, tanto indígenas como mestizas. Tales videos, narrados por niños, presentan cápsulas con información como festividades, gastronomía, medicina tradicional, mitos y leyendas de comunidades indígenas o, como dice la presentación de dicho proyecto, de un "grupo cultural con identidad particular" (Comisión Nacional para el Desarrollo de los pueblos Indígenas). ${ }^{4}$

Algunos aspectos de este material son un comentario relevante sobre la situación económica y cultural en el contexto del México moderno. Por ejemplo, el video de los mazahuas (Michoacán y Estado de México) "Cosechando y saboreando" habla sobre el cultivo del maíz. El narrador, el niño mazahua Omar Téllez, menciona algunas de las variedades de maíz y explica cómo es la tradición de la cosecha. En ella participa toda la familia (abuelos, padres e hijos). Una vez cosechado, la abuela se encarga de prepararlo para hacer tortillas. El video cierra con toda la familia reunida alrededor de la fogata lista para almorzar mientras el abuelo cuenta historias. Este cuadro es un tanto idílico si se contrasta con algo que el narrador dijo al inicio y con la situación del campo mexicano en la actualidad: “Aquí sembramos maíz. Antes lo vendíamos pero ahora pagan tan poco por él que ya sólo sembramos el maíz que nos vamos a comer durante el año".

Analisa Taylor explica esta crisis partiendo del abandono del estado proteccionista con el expresidente Carlos Salinas de Gortari y la firma del TLC. El PRI (Partido Revolucionario Institucional) se reservó la propiedad de las tierras y desmanteló el control de precios de productos agrícolas básicos, de esta manera los pequeños agricultores

4 Los videos aquí comentados se encuentran en el sitio web de esta comisión, excepto "Chinos de Mexicali” que está disponible en YouTube.

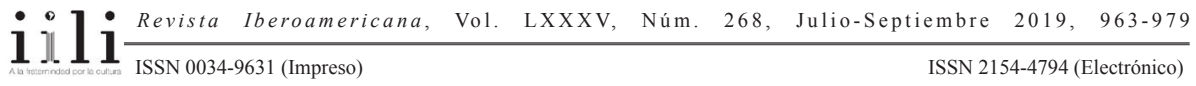


se volvieron una especie de refugiados económicos en su propio país e incrementó la emigración a Estados Unidos de manera indocumentada. Como resultado, para finales del siglo XX, el gobierno mexicano abandonó la soberanía alimenticia del país (Taylor 6). El maíz, así como otros productos básicos se importaron de Estados Unidos (Barry citado en Taylor 6). Cabe resaltar que esta situación no se dio de un momento a otro sino que ya se venía gestando en administraciones anteriores:

Yet this dramatic departure from the Project of revolutionary nationalism was not as sudden as it may have appeared, but was preceded by a decade of dismantling of the cultural, educational, and social welfare programs that had lent a veneer of domestic stability and international credibility to the PRI throughout its nearly seventy-year rule. (Taylor 6)

Al respecto Noam Chomsky señala que uno de los objetivos del TLC era desplazar a la gente de su tierra porque los mexicanos no deberían de producir maíz, ¿por qué? Porque el agronegocio altamente subsidado de Estados Unidos lo puede producir más barato: "Therefore, Mexicans should go off into the cities and find jobs that are not there, and in fact, start coming across the border because there is no way for them to survive. That is part of NAFTA" (76).

Por otro lado resulta interesante ver el cambio de perspectiva hacia los grupos indígenas. Si antes se intentaba acercarse a ellos para que asimilaran la cultura occidental y el nacionalismo homogeneizante, ahora interesa que estos mismos pueblos conozcan más de su cultura, y por lo tanto se destaca el conocimiento de las lenguas indígenas. En los videos, independientemente del tema a tratar (cultivo del maíz, trajes típicos o medicina tradicional), se menciona el dominio o no de la lengua de los ancestros. Así por ejemplo en el video del maíz comentado anteriormente, el narrador declara que sólo habla algunas palabras del mazahua, sin embargo entiende a sus abuelos, quienes son monolingües.

Otro ejemplo sobresaliente se encuentra en uno de los videos correspondientes al grupo chocholteco del estado de Oaxaca titulado "Recuperando nuestra lengua". En él se dice que sólo unos pocos ancianos hablan chocholteco y se está tratando de que los niños lo aprendan y que incluso se lo enseñen a sus padres. Dos de estos padres, en edad madura, dan su testimonio respecto al uso de las lenguas indígenas. Uno de ellos explica: "nos decía el maestro 'ya no hables eso, habla español' y pues puro español, nos olvidamos de la lengua materna". Otro sostiene que fue ignorancia de los padres, quienes no les inculcaron ni insistieron en hablar su lengua indígena. Por otro lado, se subraya la labor de dos personas de la comunidad por rescatar esta lengua, un anciano, don Urbano, quien escribió un diccionario, y Juanita, tía del narrador. Ésta última aprendió de la abuela Carmen, de quien transcribe oraciones en chocholteco. Juanita enseña esta lengua a los niños que están interesados. Llama la atención que de pasada

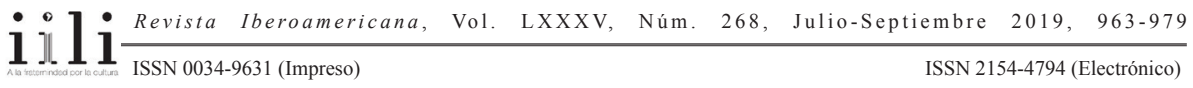


se hable de los maestros de antaño que no querían el uso de las lenguas originarias, sin embargo no hay ningún comentario a los supuestos programas bilingües o de cuál es la opinión/discurso del maestro actual en esas comunidades.

Al respecto, Fernando Soberanes Bojórquez, coordinador de proyectos alternativos para la Coalición de maestros indígenas y promotores de Oaxaca, sostiene que el currículum de la llamada educación indígena contribuye a la extinción de las lenguas y culturas de los pueblos originarios. Explica que hay una separación entre la vida de la gente y la que se vive/enseña en las escuelas a los niños y jóvenes. Aunque la comunidad sea rica en recursos naturales, no se les enseña a cuidarlos y aprovecharlos. Aunque los niños sean bilingües o monolingües en lenguas indígenas se les enseña y evalúa en español a través de programas estandarizados. De la misma manera, el gobierno usa la retórica de una educación bilingüe e intercultural para los pueblos indígenas, sin embargo, esto debería de ser para toda la población. Los miembros más jóvenes de las comunidades ni entienden ni hablan la lengua de sus ancestros, a pesar de las escuelas indígenas que supuestamente son bilingües. Por ello, se han creado proyectos independientes como los "nidos de lengua" donde, con el acuerdo de la comunidad y de los que conservan su lengua (los mayores), se designa una casa donde se hacen actividades rutinarias en la lengua que se quiere recuperar, participan los niños en edad preescolar (preferentemente antes de que sepan hablar) y estas actividades se dirigen únicamente en lengua indígena (Soberanes Bojórquez 102, 103, 107 y 111).

Por otra parte es importante mencionar que estos videos vienen acompañados de cuadernos de trabajo donde, a través de la información proporcionada y actividades, se invita a la reflexión crítica. A manera de ejemplo, el cuaderno que acompaña al video sobre el pueblo chontal de Tabasco, pide que después de verlo el niño investigue, dialogue, cuestione y debata con compañeros de clase porque:

si lo haces, estarás propiciando el surgimiento de una sociedad comunicativa en la que todos contemos nuestras cosas con claridad y escuchemos con atención las cosas de otros. No olvides el importante papel que juegan el debate y el diálogo intercultural en la vida de los pueblos y en la construcción de la democracia y del conocimiento. (Chapela 10)

Aligual que la insistencia en rescatar las lenguas indígenas, obviando la incoherencia de este discurso con lo que ha tratado de hacer la educación en cuanto a las poblaciones originarias, resulta paradójico que también se insista en llamar a cada pueblo por su verdadero nombre ya que por siglos, los pueblos indígenas de México han sido llamados con nombres que no les corresponden, en ocasiones tales nombres resultan ofensivos. De los cuadernos de trabajo se destaca la siguiente cita: "lo importante es que nuestra sociedad nacional necesita aprender a llamar a los pueblos indígenas por su nombre verdadero: el nombre que ellos mismos reconocen, el nombre que heredaron

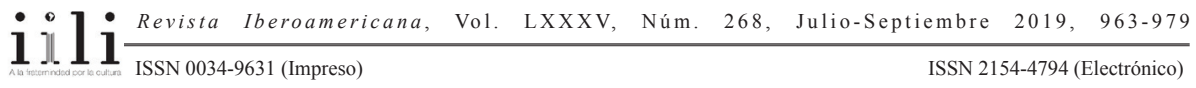


de sus antepasados, su nombre ancestral, milenario" (Chapela 11). Algunos ejemplos ofrecidos son: p'urhépechas de Michoacán, a los que antes se les llamaba "tarascos" que significa "cuñado", y a los wixárika, a los que antes se les llamaba huicholes y cuyo significado es "los que huyen" (12).

Las reflexiones, las actividades y la información de los videos son valiosas, sin embargo siguen estando mediatizadas por el gobierno y la SEP. Pareciera que hay un guión escrito de antemano para que los niños lo repitan, queriendo dar la apariencia de que son los narradores los que eligen los datos para compartir con niños de otras comunidades. También, aunque en apariencia se le da un lugar más importante a la historia de estos pueblos en el contexto nacional, se les sigue subordinando a lo que ha querido verse como una identidad mexicana representada con símbolos tales como la bandera o el himno nacional. Dos ejemplos que destacan son: "En la escuela" de los chontales de Tabasco y "Vistiendo la tradición" del pueblo amuzgo del estado de Guerrero. El primero cuenta que en la escuela aprenden costumbres de su pueblo y hablan en su lengua originaria, además: "hasta tenemos el orgullo de cantar el himno nacional en nuestro idioma", cierra este video por supuesto con un coro de niños cantando el himno nacional en chontal. En el segundo, del pueblo amuzgo del estado de Guerrero, "Vistiendo la tradición", la narradora, Eliseida, presenta los trajes tradicionales: huipil para la mujer y cotón y calzón para el hombre. Los hay de dos tipos, según cuenta la narradora, uno para el trabajo y otro para ocasiones especiales. Así, con música de fondo del trío los Xochiltecas que entonan la canción "huipil de Xochistlahuaca", se ven imágenes de hombres y mujeres portando el traje para ocasiones especiales en honores a la bandera donde algunas niñas forman parte de la escolta.

Cabe mencionar aquí lo que Soberanes Bojórquez apuntó sobre educación indígena, sostiene que este término implica subordinar la indigenidad a un plan educacional y convertirlo en marginal o secundario: "This is like saying: we are going to convert you into a good Mexican, fully Westerinized, but we will permit you to wear your huipil when you want to or include in your vocabulary some Zapotec words" (Soberanes Bojórquez 122). En este caso se trata de una sociedad multicultural donde las culturas coexisten y son admiradas, sin embargo no gozan de un verdadero reconocimiento, es una sociedad multuricultural pero no multiculturalista (Crowder 12).

Por otra parte, un elemento importante de algunas comunidades indígenas como en Oaxaca es el denominado "comunalidad". Según explica Jaime Martínez Luna, la comunalidad es el cuarto principio que integra el acta estatal de educación a partir de 1995. Se suma este principio junto a democracia, nacionalismo y humanismo. El que se haya incluido este aspecto propio de algunos pueblos originarios obedece al deseo de integrar contenidos específicos, locales y regionales en la educación que se imparte en todo el territorio oaxaqueño. Se pretende reforzar el conocimiento ancestral por medio de agencias pedagógicas y herramientas apropiadas para resistir el destructivo conocimiento individualizador. La comunalidad destaca que nadie enseña a nadie sino

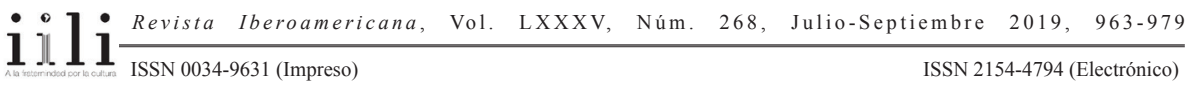


que se aprende de unos y otros para resolver necesidades. Es una manera de entender la vida como un ser permeado de espiritualidad, simbolismo y una integración más grande con la naturaleza (Martínez Luna 90, 91 y 94). El video del pueblo chocholteco de Oaxaca "Haciendo tequio" explica que dar tequio es un trabajo voluntario comunitario en beneficio de la misma comunidad. Algunos ejemplos que se observan en este video son la pavimentación de calles, la construcción de un bachillerato y la comida que algunas mujeres preparan para darles a los que participan en la obra. Sin embargo, se presenta como sólo un servicio comunitario en labores específicas como la construcción o la pavimentación de calles, algo que forzosamente implica un trabajo en equipo. No se observa como una parte de la vida cotidiana donde cada decisión tendría que tomarse de acuerdo a ese sentido de comunalidad y no a nivel individual.

\section{El AUGE DE LA MULTICULTURALIDAD}

Como se presentó anteriormente, ha habido un interés en volver hacia las raíces indígenas a partir de la Revolución, pero siempre bajo la idea de lo nacional. En este sentido, como sostiene George Crowder, cuando se trata de responder a la diversidad cultural, en el modelo del nacionalismo conservador se espera que todos los ciudadanos rindan honores a una identidad nacional sustancial, lo cual implica una aceptación no crítica de sus instituciones tradicionales, valores y mitos (84). Dicho de otra manera y en palabras de C.W. Watson: "Multiculturalism and nationalism may not be intrinsically related, but it is certainly the case that in the twentieth century at least they have been awkwardly and dangerously entangled" (18).

El indigenismo ha sido parte de este programa, es decir, las investigaciones sobre pueblos indígenas, la divulgación de los resultados y la creación de programas, especialmente educativos, corrían a cargo de profesionistas formados en la cultura occidental y trabajando para el estado. Como sostiene Taylor "... a social scientific paradigm wedded to a set of government institutions and policies as well as an aesthetic sensibility that has shaped a great deal of twentieth century Mexican art and literature" (1-2). Esto se ha observado a través de diversas instituciones como el INAH, ENAH o el INI, ésta última desaparecida bajo el sexenio de Vicente Fox. ${ }^{5}$ Estas instituciones, según explica Taylor, aspiraban a servir a las actividades indigenistas. Los estudiosos del INI, por ejemplo, trataban de acercar a los pueblos indígenas a la sociedad mestiza e hispanohablante y también sirvió para canalizar su participación en la esfera nacional en maneras que resultaran ventajosas para el partido en el poder: "Indigenismo has been an important mechanism for consolidating the power of the Institutional Revolutionary

Instituto Nacional de Antropología e Historia, Escuela Nacional de Antropología e Historia, Instituto Nacional Indigenista

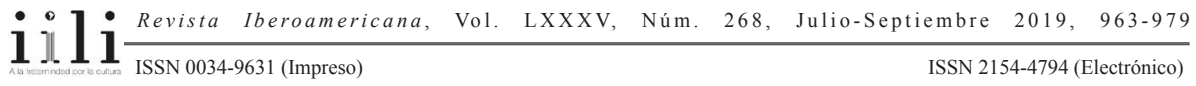


Party (PRI) and delineating the parameters of modern national subjectivity" (Taylor 13). Es relevante destacar esto porque a pesar de que el indigenismo ha desaparecido de las políticas del estado, las tensiones entre el gobierno y las comunidades indígenas permanecen en el presente. Siguiendo el análisis de Taylor, el indigenismo ha ejercido una violencia epistémica al observar al indígena como otro y proyectarlo en términos espirituales, pero como periférico de la nación. Asimismo, al anclar el sentimiento nacionalista en ideales de valor y dignidad precolombinos, y al mismo tiempo considerar a los indígenas contemporáneos como dependientes más que protagonistas, les niega la posibilidad de tener su propio proyecto histórico. De esta manera, el indigenista es como un intérprete cultural improvisado (Taylor 20, 25).

Las interpretaciones que se hacen de las culturas indígenas se quedan en la superficie y no se conectan de manera significativa con el acontecer histórico de la nación. Así por ejemplo, los videos aquí analizados ofrecen datos antropológicos e históricos que se quedan en la superficie porque están delimitados por varios factores: la SEP, que es el sistema oficial de educación elemental y media. Es a través de esta institución que la cosmovisión de los pueblos originarios "se da a conocer", no es que los pueblos se acerquen a ella para ofrecer su bagaje cultural y que sea difundido por medio de ella y/u otros medios; la limitación del tiempo que exige una producción de video y los alcances que persigue (que los niños de educación elemental conozcan a otras comunidades). Por estas limitantes no hay lugar a la reflexión respecto a los datos presentados y cómo se pueden conectar los muchos videos que conforman esta serie. Como sostiene Taylor, el indio es un ser que se identifica por diferenciadores que marcan la cultura como ropa, manera de preparar la comida o prácticas espirituales (28).

Por otra parte Claudio Lomnitz en Exits from the Labyrinth, sostiene que para realmente entender una cultura es necesario estudiar las relaciones espaciales, de intercambio de símbolos entre diferentes regiones y, sobre todo, ver por encima de lo que se ha creado artificialmente como "identidad nacional". Este autor destaca lo que denomina región cultural, misma que define como una cultura que existe y opera en un espacio que está organizado -y articulado- por la dominación de clase. Es decir, que la dominación de clase implica formas de organización de sistemas espaciales. Estas formas de organización en turno implican reunir a varios grupos culturales en relaciones de poder, mismas que garantizan una cierta unidad de significado dentro de la diversidad cultural implícita en la segregación espacial de clases y grupos étnicos (Exits 26). Esto refuerza la idea presentada anteriormente respecto a la intención de proyectar a México como un país diverso, pero esta diversidad se ve enmarcada/ delimitada por el aparato de educación oficial. La multiculturalidad presentada en los videos estaría entonces en relación de poder con el estado que pretende mostrar una unidad de significado.

Por otro lado es importante destacar una de las claves que Lomnitz observa en el proceso de hegemonía: la manipulación de la mitología nacional (Exits 27). Esta

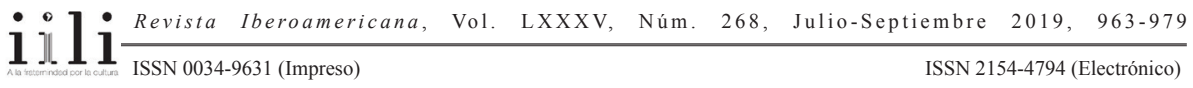


manipulación/apropiación de una mitología por parte del estado a través de la SEP se observa en el video "Cosechando y saboreando" comentado anteriormente. Al hablar del cultivo del maíz el estado tiene que aceptar que su cultivo ya no es el sustento de la comunidad y ahora se siembra solamente para autoconsumo. Se obvian los motivos y la gran responsabilidad que ha tenido el estado, pero además presenta una escena un tanto idílica de la familia alrededor de la fogata y el abuelo contando historias, ejerciendo/ actuando la cultura de la tradición oral, tan importante en los pueblos indígenas. Así, al tomar un aspecto de las culturas originarias se hace un mito de una situación precaria y se pretende presentarlo como parte de "nuestras tradiciones". Lo que se observa aquí es que se han separado las demandas socioeconómicas de las culturales, es decir, que no se concibe el multiculturalismo como integral (Wieviorka 886). El video 'rescata' la tradición del cultivo del maíz como una manifestación cultural, pero sin recibir la remuneración económica que se espera con esta práctica.

Cabe destacar que aunque el estado dejó a un lado la imagen paternalista con la llegada de tecnócratas al poder que pretendieron abrir a México a la comunidad económica global, y que luego Vicente Fox desmantelara el INI, no ha dejado de posicionarse como figura que salvaguarda la identidad nacional (posesión del estado sobre las comunidades) y por lo tanto manipula los elementos culturales a su favor. Estos videos fueron lanzados durante la administración panista pero se percibe el espíritu nacionalista promovido por el PRI (sobretodo en videos como el comentado respecto a la vestimenta tradicional de gala para hacer honores a la bandera). También, aunque la participación de los indígenas está creciendo en circuitos intelectuales, esta participación aún permanece marginal y dependiente de los intelectuales mestizos que son mediadores y promotores (Taylor 110). Así, en los videos de Ventana a mi comunidad aunque son los propios habitantes de las comunidades los que narran, el contenido, la estructura y la distribución, están dirigidos por la SEP con un equipo profesional de antropólogos e historiadores.

Por otra parte, es importante mencionar un evento que Analisa Taylor destaca porque la fecha es muy cercana a los videos y el análisis que hace es muy pertinente en esta serie. Se trata de la presentación del mapa "La diversidad de culturas de México" que señala las regiones, las comunidades y las lenguas indígenas que coexisten en México. Este proyecto fue auspiciado por la SEP y el CONACULTA (Consejo Nacional para la Cultura y las Artes) y fue presentado en el Museo nacional de antropología e historia en el año 2000. La autora reconoce que la propuesta se aleja del concepto de indigenismo que veía a los pueblos como homogéneos e infantilizados, y al mismo tiempo el estado se aleja del indigenismo oficial y de sus políticas de asimilación moviéndose hacia una nueva afirmación oficial de pluralismo cultural (Taylor 105). Sin embargo con el lanzamiento de este mapa y la serie Ventana a mi comunidad, el estado se ratifica en su estatus de dominación de conocimiento. En varios videos los niños dicen "a que no sabías esto" o "hay fruta que de seguro tú ni conoces", como en el video "Día de

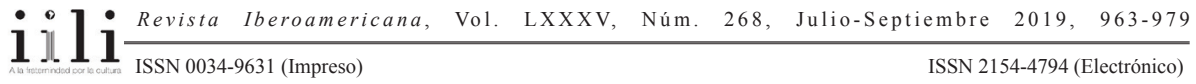


plaza", con ello se comenta la ignorancia del sector urbano respecto a las comunidades indígenas rurales. Es decir, es por medio de proyectos como estos que los niños de la ciudad se enteran, o sea que sin la mediación del estado este acercamiento no sería/ habría sido posible.

Aunque esta serie tiene mérito al difundir a gran escala partes de las culturas que integran el país, en realidad esto obedece a la interculturalidad como parte del contexto global. De acuerdo con Noam Chomsky, es sólo otra estrategia por parte del estado y de las clases dominantes para controlar: "They will resist, and one of the forms of resistance is to try to take over and distort and modify the efforts of liberation for their own purposes. So yes, that can happen with multiculturalism and diversity" (65). Asimismo, Marcela Tovar Gómez, profesora de la Universidad Pedagógica Nacional de México, subraya que las propuestas educativas han tomado el concepto de interculturalidad como política del estado desde los 90 . Sin embargo, continúa, es difícil aceptar esta agenda como diferente de la campaña de castellanizar (enseñar la lengua española) y aculturar, en primer lugar porque las nuevas ideas son desarrolladas por la misma institución que ha tenido por misión erradicar las culturas indígenas (Tovar Gómez 182). Esto cobra relevancia cuando se observa que los videos están completamente en español con algunas frases en alguna lengua originaria. Nuevamente es lo indígena lo que está separado de la población mestiza y blanca, y son los indígenas los que, de acuerdo con la visión del estado, deben de explicarse a sí mismos a esa población que los ignora. Asimismo cuando se pretende implementar un enfoque intercultural, de acuerdo con Tovar Gómez, el sistema nacional de educación piensa que es momento de "rescatar" y dar a conocer a los pueblos indígenas a través de la tradición oral. Sin embargo, continúa Tovar, estas historias están descontextualizadas y ajustadas al español, pero se aceptan como testimonios que revelan el pensamiento y cosmovisión de los pueblos indígenas. Además estas historias se interpretan con base en esquemas culturales y estructuras que no corresponden a aquellas que auténticamente organizan su contenido y su significado profundo (Tovar Gómez 183-184).

Por otra parte, subyace la idea de un relativismo cultural el cual se apoya en la noción de que las culturas son valiosas no sólo instrumental sino intrínsecamente. El relativismo cultural establece que no hay reglas morales universales en aplicación y autoridad, sino que son relativamente válidas desde un determinado punto de vista, por ello todas las culturas deben de ser igualmente respetadas (Crowder 7). El cuadernillo del pueblo lacandón explica el concepto de cultura para seguir con una sección sobre diversidad cultural que dice:

pero la realidad cambia de lugar a lugar, de momento a momento, de circunstancia a circunstancia. Por eso no puede existir una sola cultura, porque la realidad es diversa. Por eso todas las culturas del mundo son buenas, porque responden con calidad a cada

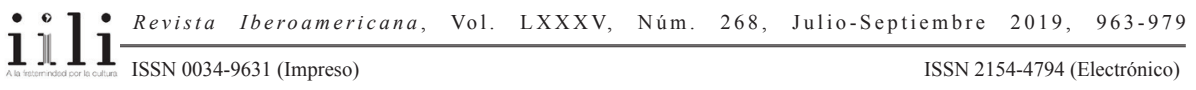


una de las distintas realidades, por eso no hay una cultura superior a otra. (Chapela, Pueblo lacandón 9, énfasis en el original)

Resalto lo anterior porque, como sostiene Gómez Tovar, la idea de multiculturalidad o diversidad cultural se queda en la retórica; si bien las actividades propuestas podrían ser de provecho, cabe preguntarse cuántas (si las hay) escuelas están estudiando este material cuando hay gran cantidad de contenidos a cubrir para que los niños se entrenen y aprueben las pruebas ENLACE. ${ }^{6}$ Como se dijo anteriormente, a los estudiantes se les enseña en español y se les evalúa a través de programas estandarizados, como apunta Soberanes Bojorquez: "The Alliance for Educational Quality (ACE) is the most recent example of an education policy in which the linguistic and cultural diversity of Mexico are not recognized. And it is not that the policy speaks against diversity; rather, once again, original peoples are simply and completely forgotten" (103). ${ }^{7}$

Se observa aquí una mediación en la proyección de la multiculturalidad en el estado moderno. En diferentes periodos se ha visto cómo se ha querido integrar a los diversos pueblos de México a la idea de un país moderno por medio de los programas oficiales de educación, o bien intentar una aproximación multicultural y presumiblemente alejada de la imagen paternalista del estado como los videos aquí analizados. Se trata de una mediación de la modernidad, definida por Lomnitz como: "cualquier apropiación de la ideología de la modernidad por un régimen o por actores sociales especificos que piensan aplicarla selectiva y parcialmente, ya que el actor social en cuestión utiliza la utopía abstracta de la modernidad para implementar políticas hibridas que modernizan y desmodernizan a la vez" (Modernidad 12, original en itálicas).

Así, mientras en 2006 cuando se lanzó la serie Ventana a mi comunidad se consideró pertinente difundir las investigaciones sobre los pueblos originarios con que contaba la SEP e incluirlas en las actividades de clase, en la Alianza por la Calidad de la Educación, comentada por Soberanes Bojórquez, se hace a un lado esta intención para dar cabida a los programas estandarizados que se tratan de ajustar a los niveles internacionales y que colocarían a México en la lista de países modernos. Se infiere por este cambio (de Ventana a mi comunidad a ACE) que persiste la idea de que lo indígena es lo que retrasa la llegada del país a la modernidad y al progreso. Como comenta Lomnitz, el declive del auge del indigenismo se provocó por el examen de los aspectos políticos del viejo dilema de los misioneros del nuevo mundo, es decir: "al igual que Diego de Landa, los indigenistas estaban preservando a la cultura indígena en sus textos y museos

6 Evaluación Nacional de Logro Académico en Centros Escolares. Es una prueba del Sistema Educativo Nacional que se aplica a escuelas públicas y privadas de México (SEP Gobierno de la República).

7 Alianza firmada en mayo de 2008 por el Gobierno Federal y el Sindicato Nacional de Trabajadores de la Educación que se centra principalmente en la modernización de los centros escolares y la profesionalización de profesores y autoridades educativas (Amador Hernández 1-2). 
para luego acabar con ella en la sociedad" (Modernidad 89). Taylor observa la misma situación con el mapa de la diversidad cultural comentado anteriormente, al sostener que el alejamiento del indigenismo hacia la multiculturalidad se entiende como una estrategia para manejar y re-direccionar las propuestas radicales de estos movimientos en maneras que no alteren las relaciones básicas de poder entre los dominadores y los dominados: "it is in this sense that the denouement of official Indigenismo looks a lot like its beginning in 1940s Mexico" (112).

El multiculturalismo en México, como lo muestran los ejemplos anteriores, se ha evocado a lo político, es decir, como señala Michel Wieviorka, al análisis de las instituciones y formas políticas a través de las cuales se establece el principio de multiculturalismo entendiendo su surgimiento y funcionamiento, o bien evaluando sus efectos. De esta manera, continúa este autor, el indigenismo de los años 40 y 70 trataba de controlar la participación indígena más que reconocer sus demandas (886).

La multiculturalidad en la retórica nacional, como en la descripción del país en la Constitución o en la serie Ventana a mi comunidad es, como sostiene Chomsky, sólo una estrategia de dominación del capitalismo neoliberal (65). ${ }^{8} \mathrm{Si}$ en la era de la globalización impera la retórica de la diversidad cultural, entonces un país que aspira a cumplir con los estándares internacionales de educación y economía, no puede quedarse fuera de esta retórica. Sin embargo, como explica Lomnitz, la novedad histórica que enfrentamos no es la multiculturalidad, sino el hecho de que ésta emerge hoy en el marco del estado-nación, forma política que desde sus inicios ha pugnado por homogeneizar las diferencias culturales (Modernidad 67). El análisis de esta lucha por homogeneizar lleva a Gareth Williams a indicar que las élites han aplicado la noción de "etnicidad ficticia", en su relación con la sutura de la noción del pueblo, a los proyectos y diseños de la modernización capitalista (35-36).

La etnicidad ficticia es, como explica Etienne Balibar, la fabricación de la idea de una etnia para las formaciones sociales nacionalizadas, es decir, representadas en el pasado o en el futuro como si formaran una comunidad natural que posee en sí misma identidad de orígenes, cultura e intereses que transcienden las condiciones individuales y sociales. La etnicidad ficticia, continúa Balibar, permite que la expresión de una unidad preexistente sea vista en el estado y se mida continuamente a la luz de su misión histórica al servicio de la nación, y como consecuencia se idealice la política (96).

Por ello la función del lenguaje, la literatura y del intelectual ha sido la de producir y promover un marco cultural común entre grupos lingüísticos, clases, regiones y etnias. Por lo tanto los procesos de modernización económica tales como la literatura,

8 El artículo segundo de la Constitución sostiene que la nación mexicana tiene una composición pluricultural que se sustenta originalmente en sus pueblos indígenas (Constitución Política). Se incluyó esta descripción en el gobierno de Carlos Salinas de Gortari, 1988-1994 (Wieviorka 886).

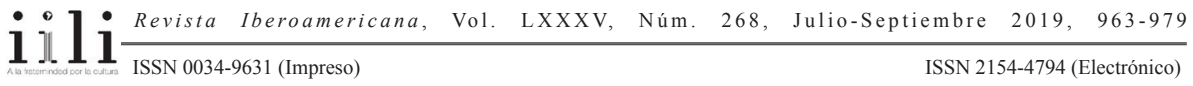


artes visuales, radio y cine se han institucionalizado como procesos simbólicos en la representación de poder del estado y de reproducción hegemónica (Williams 37).

En este contexto es evidente que en los videos de Ventana a mi comunidad hay una fragmentación que deja fuera lo propuesto por Claudio Lomnitz, que es el estudio de las culturas a través de sus relaciones espaciales y temporales así como el intercambio y manejo de símbolos. Si bien hay una idea de multiculturalidad al contar con una amplia colección de videos de las diferentes culturas en México, permea el sentido de homogeneización que señalan Williams y Balibar al suscribir a todos lo pueblos a la idea de nación. Se les suscribe primeramente por medio de la lengua dominante, pero también por medio de la simbología explícita (el himno nacional o los honores a la bandera) e implícita (el sistema oficial de educación y las diferentes instituciones gubernamentales que colaboraron, como el INAH).

Así, dado que la multiculturalidad está enmarcada dentro del control del estado, se le puede dar apertura a otras identidades en el país que no han estado suscritas a la polaridad indígena-europea o mestiza, como es el caso de los chinos en Mexicali. Parafraseando lo comentado anteriormente por Soberanes Bojórquez, se celebra la manifestación de otras culturas por medio de festividades, tradiciones culinarias o vestimenta, entre otros elementos, pero bajo la primicia de "ser mexicano". En otras palabras, la etnicidad ficticia puede presentarse con una gran dosis de multiculturalismo, mismo que está desarticulado pero cuyas piezas están controladas por el aparato estatal a través de sus instituciones.

Conocer para desconocer, para asimilar a la identidad mexicana construida por las élites intelectuales, parece ser la primicia en la agenda cultural mexicana a lo largo de la historia. Con interés y rechazo se han manipulado varios de los elementos de las culturas originarias para adaptarlas a la imagen de nación en momentos determinados. En años recientes el concepto de multiculturalismo se vio plasmado en proyectos como los videos aquí analizados o el mapa de "la diversidad cultural de México", mismos que evidenciaron la infantilización y simplificación con las que se había tratado a esas culturas en administraciones pasadas. Sin embargo se denota un continuo posicionamiento de la cultura institucionalizada que decide cuándo integrar y cuándo descartar, como lo evidenciado en la serie Ventana a mi comunidad y en ACE. Como se muestra en "Recuperando nuestra lengua", la SEP (y todas las instituciones que respaldaron el proyecto) se encontró con la casi extinción del chocholteco, es decir, el estado se encontró con las ruinas que desde la colonización, y pasando por diferentes administraciones, se han hecho del bagaje cultural de los pueblos indígenas. Cabe preguntarse: ¿qué interés tendrán los maestros en incluir en sus clases materiales como Ventana a mi comunidad cuando hay una preocupación por conservar su empleo o bien, competir por una plaza permanente en base a la aprobación de exámenes, mismos que seguramente no versarán en la comprensión de las culturas indígenas, a menos que su área sea específicamente preescolar o primaria indígena? El panorama de la educación

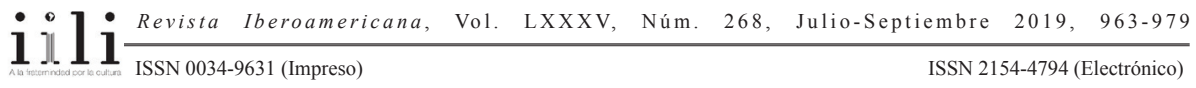


oficial no es muy alentador, sin embargo cabe enfatizar que hay una gran labor por vivir desde otra perspectiva de las culturas originarias que se lleva a cabo desde las mismas comunidades. Tal es el caso del estado de Oaxaca a través de los nidos de lengua, o el comité independiente Melendre ${ }^{9}$ cuyo quehacer no se limita a aprender una lengua o una tradición, sino a resolver las diferentes necesidades económicas, sociales y familiares a partir de recursos propios, y donde la multiculturalidad se vive día a día a través del movimiento migratorio en el que, al regreso a la comunidad de origen, de visita o permanentemente, se van integrando nuevas perspectivas que implican un cambio constante en varias áreas de dicha comunidad.

\section{OBRAS CITADAS}

Aguilar Camín, Héctor y Lorenzo Meyer. In the Shadow of the Mexican Revolution: Contemporary Mexican History, 1910-1989. Austin: U of Texas P, 1993.

Amador Hernández, Juan Carlos. "La alianza por la calidad de la educación: modernización de los centros escolares y profesionalización de los maestros". Centro de Estudios Sociales y de Opinión Pública 74 (2009): 1-36.

Balibar, Etienne. "The Nation Form: History and Ideology". Race, Nation, Class. Ambiguous Identities. Chris Turner, trad. Etienne Balibar e Immanuel Wallerstein. Londres: Verso, 1991. 86-106.

e Immanuel Wallerstein. Race, Nation, Class. Ambiguous Identities. Londres: Verso, 1991.

Chapela, Luz María. El pueblo chontal de Tabasco. México, DF: Secretaría de Educación Pública, 2006.

El pueblo Lacandón. México, DF: Secretaría de Educación Pública, 2006.

El pueblo mazahua. México, DF: Secretaría de Educación Pública, 2006.

"Chinos de Mexicali". YouTube, publicado por Beatriz Adriana Espinoza Rojo, 16 junio 2013. $<$ www.youtube.com/watch?v=mx9jlzdrkxc $>9$ abril 2015.

Chosmsky, Noam. "The Imperial State and Hope from inside Indigenous America". New World of Indigenous Resistance. Noam Chomsky and Voices from North, South, and Central America. Lois Meyer y Benjamín Maldonado Alvarado, eds. San Francisco: City Lights, 2010. 65-82.

Comité Melendre. <www.comitemelendre.blogspot.com>. 20 enero 2014.

Constitución Política de los Estados Unidos Mexicanos. Cámara de Diputados del H. Congreso de la Unión, 2012. <www.diputados.gob.mx/leyesbiblio/ref/cpeum. htm>. 05 oct. 2012 .

9 Melendre es un comité formado por jóvenes zapotecas en 2004. Entre sus objetivos se encuentran la unión del pueblo zapoteca y la recuperación de su idioma y sus variantes. Llevan a cabo servicios sociales comunitarios (Comité Melendre).

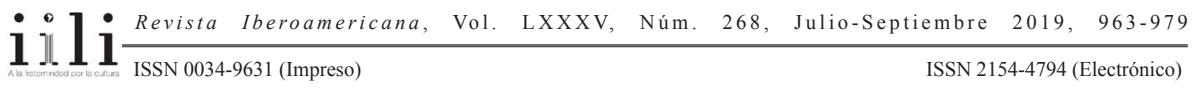


Crowder, George. Theories of Multiculturalism. An Introduction. Malden: Poly P, 2013. Editorial. Proceso, Núm. especial 43 (enero 2014): 3.

Eiss, Paul. "Deconstructing Indians, Reconstructing Patria. Indigenous Education in Yucatan from the Porfiriato to the Mexican Revolution." The Journal of Latin American and Caribbean Anthropology 9/1 (2004): 119-50.

Evaluación Nacional del Logro Académico en Centros Escolares. Secretaría de Educación Pública. <www.enlace.sep.gob.mx>. 10 abril 2015.

Joseph, Gilbert M. y Daniel Nugent, eds. Everyday Frms of State Formation. Durham: Duke UP, 1994.

Knight, Alan. "Racism, Revolution, and Indigenismo: Mexico, 1910-1940." The Idea of Race in Latin America, 1870-1940. Richard Graham, ed. U of Texas P, 1990. 71-113.

Legorreta, María del Carmen. "Las lecciones". 20 años después. El levantamiento zapatista. Rafael Rodríguez Castañeda, ed. Proceso, Núm. especial 43/1 (2014): 42-46.

Lomnitz-Adler, Claudio. Exits from the Labyrinth. Culture and Ideology in the Mexican National Space. Berkeley: U of California P, 1992.

Modernidad Indiana. Nueve ensayos sobre nación y mediación en México. México, DF: Planeta, 1999.

Martínez Luna, Jaime. "The Fourth Principle." New World of Indigenous Resistance. Noam Chomsky and Voices from North, South, and Central America. Lois Meyer y Benjamín Maldonado Alvarado, eds. San Francisco: City Lights, 2010. 85-99. Meyer, Lois y Benjamín MaldonadoAlvarado, eds. New World of Indigenous Resistance.

Noam Chomsky and Voices from North, South, and Central America. San Francisco: City Lights, 2010.

Monsiváis, Carlos. Historia mínima de la cultura Mexicana en el siglo XX. México, D.F.: El Colegio de México, 2010.

Nouzeilles, Gabriela. "The Transcultural Mirror of Science. Race and Self-Representation in Latin America." Literary Cultures of Latin America. A Comparative History. Mario J. Valdés y Djelal Kadir, eds. 3 vols. Nueva York: Oxford UP, 2004.

Nugent, Daniel, y María Alonso. "Multiple Selective Traditions in Agrarian Reform and Agrarian Struggle: Popular Culture and State Formation in the Ejido of Namiquipa, Chihuahua". Everyday Forms of State Formation. Gilbert M. Joseph y Daniel Nugent, eds. Durham: Duke UP, 1994. 209-246.

Soberanes Bojórquez, Fernando. "Noam Chomsky and Indigenous Education in Oaxaca, Mexico". New World of Indigenous Resistance. Noam Chomsky and Voices from North, South, and Central America. Lois Meyer y Benjamín Maldonado Alvarado, eds. San Francisco: City Lights, 2010. 101-113.

Taylor, Analisa. Indigeneity in the Mexican Cultural Imagination. Thresholds of Belonging. Tucson: U of Arizona P, 2009. 
Tovar Gómez, Marcela. "Political Uses of Interculturalidad: Citizenship and Education". New World of Indigenous Resistance. Noam Chosmsky and Voices from North, South, and Central America. Lois Meyer y Benjamín Maldonado, eds. San Francisco: city Lights, 2010. 179-190.

Vaughan, Mary Kay. Cultural Politics in Revolution: Teachers, Peasants, and Schools in Mexico, 1930-1940. Arizona: U of Arizona P, 1997.

Ventana a mi comunidad. Comisión Nacional para el Desarrollo de los Pueblos Indígenas. 2012. <www.canalventanaamicomunidad.tv>. 10 oct. 2013.

Watson, C.W. Multiculturalism. Philadelphia: Open UP, 2000.

Wieviorka, Michel. "Is Multiculturalism the Solution?" Ethnic and Racial Studies 21/5 (1998): 881-910.

Williams, Gareth. The Other Side of the Popular. Neoliberalism and Subalternity in Latin America. Durham: Duke U P, 2002.

Palabras clave: Multiculturalismo, identidad nacional, neoliberalismo, educación indígena, mediación gubernamental

Recibido: $\quad 9$ octubre 2015

Aprobado: 23 agosto 2016 
